\title{
Clearing the Waters of the Fracking Debate
}

\author{
ALEXI SARA ERNSTOFF, BRIAN R. ELLIS \\ Volume 1, Fall 2013 \\ DOI: http://dx.doi.org/10.3998/mjs.12333712.0001.009
}

\section{ABSTRACT}

Much of the debate on "fracking" in the United States is fueled by poor communication among stakeholders. Information in the public sphere may be provided by biased sources, and complicated academic research is often misinterpreted by media sources. The goal of this review is to provide an open-access source for a non-technical audience that facilitates a balanced discussion on the complex topics related to hydraulic fracturing and its impact on water resources. The limited information available suggests that many of the environmental concerns related to hydraulic fracturing activities may be similar to those experienced from other industrial practices. Two examples of concerns that are not unique to hydraulic fracturing include water use and chemical non-disclosure. Hydraulic fracturing well completions use similar amounts of water when compared to other energy and mining activities and undisclosed chemical additives may also be present in food and cosmetic products. The point here is not to say that water consumption and non-disclosure of proprietary chemical additives are not issues that warrant closer consideration as we continue to utilize hydraulic fracturing to pursue our domestic shale gas reserves, but instead, to highlight similar environmental challenges presented by other industrial activities. Many research and knowledge gaps remain regarding the ultimate impact of high volume hydraulic fracturing on the environment, however, the high profile nature of the fracking debate can help raise public awareness to the broader sustainability challenges associated with the efficient utilization of our water and energy resources. 
Introduction

Recent media attention on hydraulic fracturing (often referred to as fracking) for natural gas extraction sensationalizes both perceived and actual risks of the industrial practice. Unlike most industrial activities, hydraulic fracturing has drawn extensive attention from politicians, lawmakers, and the general public. This attention is driven largely by environmental and public health concerns associated with hydraulic fracturing and its related activities. In this paper we discuss several controversial issues related to hydraulic fracturing's potential impact on water resources, including the consumption of fresh water during the fracturing process, the risk of water contamination, and the safe disposal of wastewaters. Although we have limited the scope of our discussion to water-resource impacts, it is important to note other environmental concerns include such issues as the greenhouse gas impact of increased shale gas extraction (see, e.g., Weber and Clavin 2012).

The extensive scrutiny of hydraulic fracturing activities provides a unique opportunity to raise public awareness to the juxtaposition of our national energy demands and the environmental costs associated with the development of domestic energy reserves. The extraction, generation, and consumption of energy are intricately tied to our most basic necessity: water. Increased public awareness and understanding of these issues empowers citizens to engage in environmental policy decisions that affect their lives (Bäckstrand 2003).

Ideally, facts and data related to hydraulic fracturing and its risks would be plentiful, highly certain, and presented to the public in a neutral and unbiased manner. The current media blitz covering hydraulic fracturing activities and the biases of pro- and anti-fracking lobbyists have the potential to perpetuate misconceptions related to complex scientific issues (Stamm, Clark, and Eblacas 2000). People's feelings about hydraulic fracturing, formed perhaps by prior beliefs, peer interaction, or media attention, may eclipse decision-making based on analytical evaluation of risks, even when improved scientific data becomes available (Slovic et al. 2004; Druckman and Bolsen 2011). To tackle the complicated sustainability issues related to hydraulic fracturing and domestic energy extraction, it is essential for stakeholders to develop balanced opinions supported by analytical risk evaluation. Comparing alternative ways of thinking may be one way to foster balanced opinions on emerging technologies like hydraulic fracturing, and this is the aim of our paper. We offer perspective on perceived and actual risks of hydraulic fracturing to water resources and place these risks in a greater context that is intended to be accessible 
to both the scientific community and the general public. We present a simplified discussion of the lifecycle of water use in hydraulic fracturing including water withdrawal, risk of contamination to the environment, and wastewater disposal.

\section{Background and Context}

\section{Language Ambiguities and Complexity}

A clear discussion amongst various stakeholders is often required to identify and address environmental concerns related to emerging technologies (Bäckstrand 2003). However, different stakeholders within the broader discussion of hydraulic fracturing use the term fracking differently. Materials put forth by activist groups (e.g., BanMichiganFracking.org) suggest that public concerns range from the fracturing process itself to its associated activities like waste disposal and increased truck traffic - all of which appear to fall under the umbrella term fracking. Within industry, however, the term fracking (often spelled as fracing) may be used only to describe the specific activity of hydraulically fracturing a well and often excludes other associated or ancillary activities (King 2012; Pacific Institute 2012). Hydraulic fracturing stimulation is but one of the many steps necessary to access entrapped gas from impermeable reservoirs such as organic-rich shale formations. There are alternative stimulation techniques and working fluids (e.g., liquefied petroleum gas) that can be used to extract gas from unconventional reservoirs in a similar fashion (EPA 2004; Kargbo, Wilhelm, and Campbell 2010).

In addition to language ambiguities, communicating with a diverse audience about the impacts of hydraulic fracturing is challenging because of the wide variation in activities that depend on unique geological characteristics, state-specific regulations, and site-specific drilling techniques (CRS 2012; King 2012; Pacific Institute 2012). Furthermore, the academic literature assessing the potential environmental risks of hydraulic fracturing is limited and, in some cases, remains highly debated (Cathles et al. 2012; Davies 2011; Howarth, Ingraffea, and Engelder 2011; Howarth, Santoro, and Ingraffea 2011; Osborn et al. 2011a; Osborn et al. 2011b; Saba and Orzechowski 2011 Schon 2011). This high degree of variability and contention suggests a spectrum of potential environmental impacts, of which many will be site-specific. This spectrum is not well captured in the current polarized debate on hydraulic fracturing. 


\section{Emergence of Hydraulic Fracturing}

Although it has only recently come under public scrutiny, the application of hydraulic fracturing to stimulate hydrocarbon production has been used by industry since the 1940s (Montgomery and Smith 2010). Advances in directional drilling technology now allow wells to deviate from the vertical and be drilled laterally_at times extending for thousands of feet in the horizontal direction-thereby providing access to larger volumes of entrapped gas-rich reservoir rock (King 2012). Hydraulic fracturing can be (and is) used in both vertical and horizontal wells. The recent increase in the scale and rate of deployment of hydraulic fracturing, often combined with directional drilling, has prompted many of the concerns related to its potential impacts on water resources and public health. This increased level of hydraulic fracturing activity has also motivated investigations by the US Environmental Protection Agency (EPA) and the academic community (EPA 2011a; Howarth, Ingraffea, and Engelder 2011). In this paper we use the term high-volume hydraulic fracturing (HVHF) to refer specifically to the process of fracturing rock with a large volume of water (generally $>1$ million gallons) used in tandem with directionally drilled wells.

\section{Associated Geology}

Shale rocks, often the source of natural gas and oil, are formed through geologic time when fine sediments at the bottom of ancient lakes or oceans are compressed by overlying strata. Organic material, such as plant matter, is often co-deposited within these fine sediments. When subjected to compression and, subsequently, high temperatures and pressures, the organic material can decompose to form oil and natural gas, the primary component of which is methane (CH4) (Wang and Economides 2009). Shale formations can occur over a wide range of depths from surface outcrops to more than ten thousand feet below the ground, but common depths for shale-gas extraction in the United States are on the order of several thousand feet below the land surface (Fisher and Warpinski 2012; Osborn et al. 2011a).

Over geologic timeframes, gas may naturally migrate from its source shale towards the earth's surface. If this gas encounters an impermeable rock layer, it can accumulate under this formation within the pore spaces of a reservoir rock (e.g., sandstone). When this reservoir rock has sufficient natural permeability to allow for flow of gas to a drilled well, the reservoir would be considered a "conventional" reservoir and may not require extensive hydraulic fracturing to generate economic 
gas production volumes. Unconventional reservoirs, namely "tight" formations that have very low natural permeability, are being targeted with HVHF for hydrocarbon extraction. Organic-rich shale formations are a prime example of an unconventional reservoir. Exploitation of these unconventional reservoirs has greatly expanded the recoverable oil and gas reserves in the United States (CRS 2013; Montgomery and Smith 2010). These low-permeability formations have become increasingly economical to produce with the use of HVHF in combination with directional drilling techniques. Two shale formations with substantial HVHF activity are the Barnett shale in Texas and the Marcellus shale in Pennsylvania.

\section{Well Preparation and Horizontal Drilling}

The first steps in drilling a directional well for gas extraction are similar to drilling a traditional vertical well. First, a drill bores through several layers: surface sediments, the water table or subsurface aquifer(s), and underlying impermeable rocks. The vertical portion of the horizontal well stops above the gas-rich layer at the "kick-off" point. From this depth, specialized equipment enables a gradual deviation from vertical to horizontal drilling. When the bend is completed, horizontal drilling begins to access the target reservoir rock-sometimes drilling thousands of feet horizontally through shale layers as thin as 30 vertical feet (Curtis 2002).

Water is used as the vehicle for drilling mud, which is necessary to cool the bit, maintain down-hole pressure and optimize flow of material back to the surface. The volume of water required for drilling mud is only a small percentage of the total water used for completing an HVHF well (Nicot and Scanlon 2012). Drilling-mud additives are typically clays and chemical viscosifiers (King 2012).

After drilling is complete, the well must be properly cased and sealed in an effort to prevent communication between the target gas reservoir and its overlying formations. The purpose here is to maintain down-hole control of fluid flow as well as to prevent contamination of the water table (King 2012). Steel well-casing pipes are used to line the well, and cement is pumped down to the end of the pipes to back-fill the annulus, which is the space between the casing pipes and the exposed rock surrounding the drilled hole. Filling the annulus is arguably the most essential step to ensuring the integrity of the well casing and protecting water resources (CRS 2013; King 2012). Casing regulations, and specifically surface-casing regulations that intend to seal the shallow portion of the well within proximity to a water source, vary significantly from state to state (DOE 2009). Documented cases of 
groundwater contamination with methane gas have occurred due to improper or insufficient well-casing and cementing (CRS 2013; NYSDEC 2011). This known risk is not specific to HVHF, and applies generally to all oil and gas drilling.

\section{High-Volume Hydraulic Fracturing}

After the cement seal and casing are in place, the drilling rig is replaced by a temporary wellhead and the well is prepared for perforation by flushing with acid to remove cement and other debris. The well is perforated by a series of explosive charges placed at-depth along the desired well segment. The explosive charges perforate the well casing, boring through the casing and into the surrounding rock. This creates a set of small channels connecting the well to the formation. Hydraulic fracturing fluid, called slick water, is pumped into the well and forced through these channels and into the surrounding reservoir until the rock breaks into a series of fracture networks. Along the lateral stretch of a horizontal well, sections are often perforated and hydraulically fractured in series. This is one reason that high volumes of water can be required to stimulate long horizontal well segments (King 2012; Gregory, Vidic, and Dzombak 2011; Nicot and Scanlon 2012).

\section{Quantity of Water Used}

Water used for hydraulic fracturing slick water can be sourced from surface and ground water. Typically, 2-5 million gallons of water are required per well for HVHF completions (Nicot and Scanlon 2012). The total volume of water used to complete a given well varies depending on well depth and the number of hydraulic fracturing stages completed. There is no accurate estimate of national water use for HVHF. The Barnett shale in Texas, a predominate producer of natural gas in the US, required roughly 38 billion gallons of water for HVHF activity between 2009 and June 2011-with a median of 2.8 million gallons used per HVHF well. Projected future water use for HVHF in the Barnett shale is roughly 6 billion gallons per year (Nicot and Scanlon 2012).

Activists and media reports often frame the issue of hydraulic fracturing by first pointing out the high volume of water used. One response to this criticism is that HVHF makes a relatively small contribution to water demand when compared with other industries (Fracfocus 2012). Nicot and Scanlon (2012) found that HVHF water use does not substantially contribute to Texan state-wide water use. Crushed 
TABLE 1. Annual US water use (billion gallons/year) and water required per unit-energy (gallons/ MMBTU) for various energy extraction and mining activities. Year given for water use estimation

\begin{tabular}{lclll}
\hline Activity & Year & $\begin{array}{l}\text { Water use } \\
(\text { bgal/yr })\end{array}$ & $\begin{array}{l}\text { Water/energy } \\
\text { (gal/MMBTU) }\end{array}$ & Use assumptions \\
\hline Corn ethanol & 2008 & $-1,600^{3}$ & $2,510-29,100^{1}$ & irrigation, processing \\
All mining & 2005 & $-1,500^{2}$ & - & general mining \\
Nuclear & - & - & $8-14^{1}$ & uranium mining, processing \\
Oil Sands & - & - & $20-50^{1}$ & extraction, refining \\
Coal & 2003 & $<86^{4}$ & $13-32^{1}$ & coal mining, slurry transport \\
Barnett HVHF & 2011 & $-16^{5}$ & $1-3^{1,5}$ & extraction, processing \\
\hline
\end{tabular}

Values estimated from: (1) DOE 2006b; (2) USGS 2009; (3) Chiu, Walseth, and Suh 2009; (4) DOE 2006a; (5) Nicot and Scanlon 2012.

stone mining, for example, uses more water annually than that used for HVHF drilling in Texas. Table 1 demonstrates several examples of the water demands for energy and mining as well as the water use per energy output (gallons of water used per million British Thermal Units, MMBTU). When comparing the water use of different energy resources it is important to consider the amount of water consumed per unit of energy produced. As Table 1 shows, natural gas extraction and processing - even for HVHF - is generally a water-efficient energy source when compared to other energy sources such as corn-based ethanol. The irrigation of corn for ethanol production consumes thousands of gallons more water per unit of energy produced than natural gas derived from HVHF wells (Chiu, Walseth, and Suh 2009; Dominguez-Faus 2009; DOE 2006a). This preliminary analysis suggests that singling out HVHF activity as a high-volume water use may not fully capture the complexity of energy-water sustainability issues.

Another important consideration regarding water use is whether the water is effectively removed from the water cycle or simply returned in a different form. Much of the water used for HVHF either remains in the subsurface or is disposed of via deep well injection, effectively removing it from the water cycle. Water consumption in other industries may include water lost to evaporation, in which case the water is removed from immediate local use but not removed from the water cycle (USGS 2009). In the case of biofuel irrigation, for example, water that is not consumed may return to waterways contaminated with agricultural chemicals (Dominquez-Fause 2009). It is also important to note that the complete combustion of fossil fuels, such as $\mathrm{CH} 4$, leads to the production of water vapor (two water molecules produced per one $\mathrm{CH} 4$ molecule combusted), which could be viewed as an addition of new water to the water cycle. It is therefore important to consider water use efficiency (water required per unit of energy produced) and the overall 
contribution to the water cycle when assessing an energy source's impact on water resources.

In addition to the more general nationwide water and energy issues, local effects must be considered when investigating extraction of surface or groundwater for HVHF. Water withdrawal for HVHF may affect local drinking water supplies, sensitive groundwater-fed streams, and the supply of water for other industries such as farming. This is especially pertinent in drought-prone regions like the Colorado plateau and southern Texas (Galbraith 2013; Pacific Institute 2012; Nicot and Scanlon 2012). Michigan's Water Withdrawal Assessment Tool (http://www.miwwat.org) is an example of a state effort to protect regional water resources from high-volume industrial water extractions. However, this regulatory tool has its limitations. For instance, it does not consider the various industries using water from the same water source during the same time frame (Michigan Energy Forum 2012). This example highlights an opportunity to improve water-use assessment tools to better capture the local impacts of high-volume water withdrawals. At the very least, regulatory action and assessment tools regarding water withdrawals must consider local impacts and competing water demands.

\section{Chemical Use}

Slick water is generally $99 \%$ water by volume with the remaining $1 \%$ comprising chemical additives, usually less than a dozen, as well as a propping agent (often quartz sand) (FracFocus 2012). FracFocus.org supplies a list of many of the chemicals used in HVHF fluids. The exact slick water recipe is optimized based on the source water, well conditions, and materials available. The chemical additives are used for several purposes, for example, as friction-reducers to reduce required fracturing pressure (hence the name 'slick'), biocides to reduce microorganism growth within the reservoir and the well casing, oxygen scavengers to reduce pipe corrosion, and acids to remove drilling mud blockages. The proppant is used to physically prop open the shale fractures, allowing the gas to flow to the well.

Many of the concerns related to the impact of HVHF on public health and water quality are tied to the chemicals used in HVHF slick water. Industry representatives may deflect these concerns and suggest that because HVHF fluids contain $1 \%$ or less of chemical additives, these fluids present minimal risk to public health (Michigan Energy Forum 2012). As a point of comparison, domestic wastewater prior to treatment is also $>99 \%$ water (Grady, Daigger, and Lim 1999). Even if chemical additives make up less than $1 \%$ of the hydraulic fracturing fluid, the injection of 
millions of gallons of slick water for a typical HVHF completion would still involve transportation of and potential release to the environment of thousands of gallons of chemicals. It might also be argued that the chemicals in slick water are safe because they are also found in household and cosmetic products or are approved by the US Food and Drug Administration for use as food additives. However, each of these concerns and arguments comes to a central issue related to understanding risk: concentration or toxicity on its own does not quantify risk. Estimating human health risks (by assessing the probability of health damage or disease cases in a population) is dependent on the concentration of chemicals in environmental media (e.g. water), type of exposure to these chemicals (e.g., dermal contact), amount of chemical taken in by the human (e.g. milligram per day), and resulting chemical-specific (or mixture-specific) toxicity and health effects (Zartarian, Ott, and Daun 1997). Exposure to carcinogenic chemicals is a risk posed by many industrial practices and consumer products. For instance, exposure to chemicals in consumer products, such as cosmetics and even food, is under intense scrutiny from the scientific community (Dodson et al. 2012; Johnson 2002; Wagner 2003). An important factor to consider when pursuing regulation or investigation of toxic chemical exposure is the way in which members of the public are made aware of possible exposures and whether they may be able to limit their exposure due to lifestyle changes. When people choose to smoke cigarettes or use cosmetics, they can control their level of exposure to the chemicals present in these products. On the other hand, if the exposure is potentially unavoidable due to environmental contamination, as may be the case for HVHF and other energy-related pollution risks, decreasing your individual energy use may not decrease your exposure to toxins released into the environment. The latter issue emphasizes the importance of sound regulation of industrial practices that may have diffuse environmental impacts.

\section{Chemical Disclosure}

A major controversial issue related to evaluating the potential risks associated with HVHF fluid is that the names of specific chemical additives may be withheld (King 2012). It is common practice for industrial firms to keep trade secrets in order to protect their competitive edge. Federal regulations require employers in all industries to make available material safety data sheets for the chemicals employees may be exposed to, but specific chemical names may be withheld in the instance of trade secrets (CRS 2012; EPA 2011a). Food and cosmetic companies also have tradesecret protection specifically for flavors and fragrances in their products, and it is 
difficult to predict and measure exposure to these unknown chemicals (Steinemann 2011). The argument regarding the importance of disclosing chemical ingredients can therefore be broadened to industries beyond HVHF. One fundamental hurdle of environmental and exposure research is that analytical equipment used for chemical detection and quantification often requires a priori knowledge of target analytes, which means that you may have to know what you are looking for in order to detect it. In an effort to understand the occurrence of trade-secret chemical contamination resulting from HVHF activity, the EPA has developed limited strategies to detect chemicals not disclosed by gas industries. It is difficult to unequivocally link these chemicals back to HVHF (EPA 2011a).

\section{Diesel Fuel as a Chemical Additive}

An additional hurdle to understanding various industrial risks, in general, is that regulations may sometimes be unclear and inconsistently followed or enforced. Fluid injection related to gas or oil production in underground wells, such as that used in HVHF, is exempt from the Safe Drinking Water Act due to the Energy Policy Act of 2005. This exemption is commonly referred to in the media as the "Haliburton loophole." The only exception to this is when diesel additives are used in the injection fluid (CRS 2013). The EPA suggests that using diesel fuel in HVHF injection fluids poses the largest risks to waters, as this practice may lead to elevated levels of carcinogenic BTEX compounds (benzene, toluene, ethylene, xylene) in the HVHF wastewater (EPA 2004). The EPA has issued a memorandum in an effort to stop the practice of adding diesel fuel in HVHF; however, within the draft recommendations document, "diesel fuel" is defined inconsistently, and it is not clear how the recommendation will be enforced (CRS 2013). The website FracTracker (FracTracker.org/maps) shows on a map of the US the various HVHF operations that used diesel fuel in 2011 and 2012.

\section{Fracture Networks and Groundwater Contamination}

Chemical additives do not pose a risk to human health without an exposure pathway. One point of debate is whether HVHF fluids will be able to migrate vertically into freshwater reservoirs. Captured within this debate is concern among certain groups that rock fractures may be capable of reaching subsurface freshwater reservoirs. Figure 1 displays two schematic diagrams of HVHF. Figure 1(a) is a cartoon that we created to demonstrate the typical subsurface scale of HVHF activity, while 

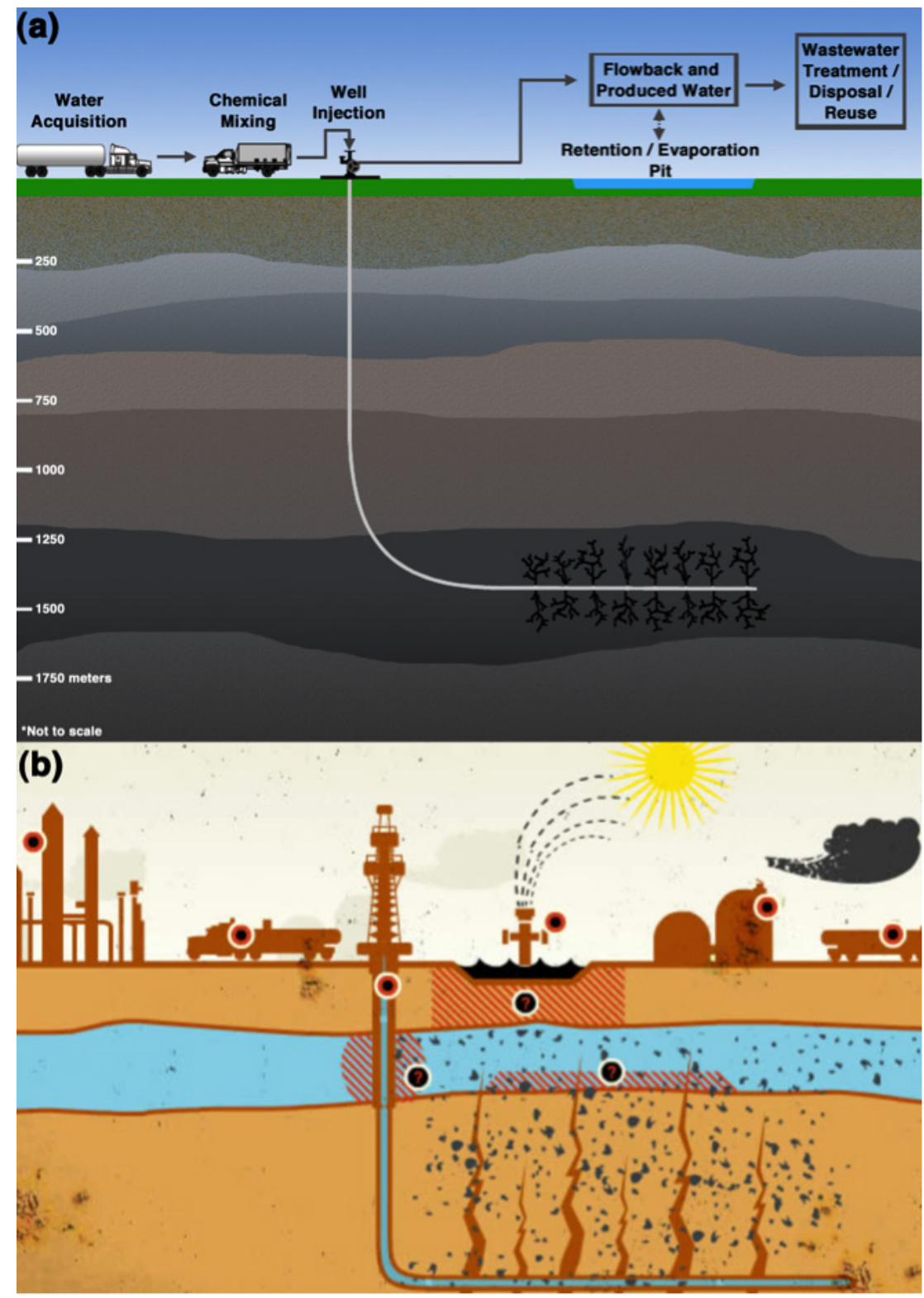

Figure 1. Contrasting images used to depict hydraulic fracturing: (a) image adapted from the EPA demonstrating the subsurface scale of typical high-volume hydraulic fracturing (surface images not to scale) (b) image used with permission from the movie GASLAND, (http://www.gaslandthemovie.com/whats-fracking). 
Figure 1(b) is provided by the Gasland movie website (GASLANDthemovie.com). Figure 1(b) depicts the horizontal well in relatively close proximity to subsurface freshwater aquifers and shows fractures extending up into the overlying freshwater aquifer-thereby suggesting that contamination is occurring due to the HVHF activity. There is no conclusive evidence that hydraulic fracturing causes contamination of aquifers from the subsurface as depicted in Figure 1(b) (Davies et al. 2012; Fisher and Warpinksi 2012; King 2012; Saba and Orzechowski 2011; Schon 2011). In stark contrast, Figure 1(a) demonstrates the depth at which the hydraulically fractured portion of the well often occurs. Although Figure 1(a) is more accurate in its scaling and depiction of a cross-section of the geologic strata, it is true that not all gas wells occur this deep. For example, coal bed methane wells and parts of Michigan's Antrim shale are atypically shallow, with production occurring at depths of less than 1,000 feet below the surface (Hopkins et al. 1995; Jenkins and Boyer 2008).

Industry data of measured microseismic activity and rock deformation due to HVHF suggest that the maximum propagation of fractures in the Barnett and Marcellus shales is around 2,000 feet in the vertical direction. These data also show that vertical fractures typically end thousands of feet below freshwater wells and also tend to have a greater degree of horizontal propagation at shallower fracturing depths (Fisher and Warpinski 2012; Davies et al. 2012). One limitation of this dataset is that no measurements were collected for the more rare situations where the water table lies within possible fracture propagation distances. Pavillion, Wyoming is an example where HVHF and water wells are within 450 vertical feet of each other. In response to residents' complaints about water taste and odor, the EPA investigated water contamination in the area. A publically released draft report of this investigation (EPA 2011a) suggests that contamination due to fracturing fluid is occurring in groundwater in Pavillion, Wyoming. Researchers are investigating further to decipher the source of contaminants in domestic water wells and to determine whether the contamination may be due to HVHF or other practices such as wastewater handling (EPA 2011a).

Although the limited data suggest that fracture propagation into freshwater reservoirs is likely more of a perceived risk than a true risk with respect to HVHF activity at typical extraction depths, it is possible that fluid migration may occur over time. Site-specific hydrology, geology, and history of other drilling must also be considered. Contaminant transport modeling may provide predictions of subsurface contaminant migration. A recent modeling study predicted that brine water from hydraulic fracturing activities could reach aquifers in approximately 100 years, and in tens of years if there are natural subsurface faults (Myers 2012). However, 
modeling efforts such as this often rely on many simplifying assumptions and may depend on site-specific parameters, so generalization of results can be challenging.

Natural processes may best predict the behavior of hydraulic fracturing fluids in the subsurface. Empirical data suggest that over geologic time there has been mixing between native Marcellus shale fluids and overlying aquifers (Warner et al. 2012). These data suggest that over very long timeframes, subsurface hydraulic fracturing fluids (not returned to the surface) may also mix with overlying aquifers. If this is true, the time scale and path of the fluid transport must be considered when estimating human exposure to HVHF-associated contaminants. However, capillary-trapping effects within the shale reservoir would likely prevent fluid movement (Engelder 2012). More data and modeling efforts are required to understand the time scale of potential fluid migration beyond the fractured reservoir and subsequent human exposure to chemical additives and naturally occurring inorganic contaminants carried in HVHF waste fluids.

\section{Gas Contamination in Groundwater}

In addition to fluid migration through fracture networks, methane gas migration to groundwater is being investigated. Due to buoyant forces, gas flows upward faster than a liquid fluid, and therefore its presence in groundwater is a quicker indicator of leakage than evidence of HVHF contaminants dissolved in water. Methane on its own is not highly toxic, but its presence in groundwater may be dangerous due to its flammability. In an effort to fingerprint the origin of methane detected in water wells, two recent studies analyzed methane in groundwater and found evidence that it originated from deep rock formations (termed 'thermogenic' methane), a finding that might link its presence to hydraulic fracturing activities (EPA 2011a; Osborn et al. 2011a). Academics and industry representatives alike caution interpreting the presence of thermogenic methane in water wells as evidence of HVHFinduced leakage because natural methane seepage is known to occur. Baseline levels of methane in drinking water prior to HVHF activity must be considered before we can conclude that the methane is due to HVHF (EPA 2011a; King 2012; Saba and Orzechowski 2011; Schon 2011). A study by Molofsky et al. (2013) analyzed Pennsylvania well water quality both before and after HVHF; the findings suggest that methane contamination in water wells existed prior to hydraulic fracturing. These researchers also found a correlation between elevated methane concentrations in well waters in valleys with lower surface topography. Confirmation of the current impacts of HVHF on groundwater contamination requires that both pre- and 
post-HVHF methane levels be measured. Increased media attention to methane contamination in drinking water may cause concerns over water-quality issues that might actually have existed prior to HVHF activity.

\section{Post-HVHF Results and Impacts}

\section{Gas Extraction and Fluid Flowback}

After hydraulic fracturing is completed, a wellhead is installed at the surface to manage the resulting flow of natural gas and other fluids up the well bore. Much of the injected slick water returns to the surface as flowback. In addition to the injected fracking fluids, a substantial amount of the brine water naturally contained within the reservoir rock will also flow to the surface. The produced gas may be directed towards an established pipeline, a pre-processing plant, or a regional underground storage rock-reservoir.

The amount of slick water and natural formation water that returns to the surface varies greatly, with estimates of below $30 \%$ to above $70 \%$ of the total injection volume coming back to the surface (CRS 2013). The greatest portion of the flowback is recovered within the first several days after hydraulic fracturing, while smaller volumes of flowback may continue with gas production. Toxic metals and naturally occurring radioactive material may be present in organic-rich shales and subsequently also in the produced water (Barbot et al. 2013; Haluszczak, Rose, and Kump 2013; Kargbo, Wilhelm, and Campbell 2010). Before disposal, flowback may be temporarily stored in pits near the wellhead site, but use of this practice varies state-by-state.

\section{Wastewater Disposal}

Current risk analyses suggest that the greatest risk of freshwater contamination from HVHF activities is associated with handling of waste fluids once they reach the surface (EPA 2011a; King 2012; Rozell and Reavan 2012). Proper handling of these fluids includes mitigating surface spills and leakage from storage pits and ensuring adequate wastewater disposal. Informal controlled studies, in which a portion of a cattle herd was exposed to HVHF flowback brine, document reproductive failure and cattle deaths due to respiratory and circulatory failure. This case study suggests but does not demonstrate that the water contamination is due to tears in the plastic 
liners of flowback storage pits. Autopsies and water testing did not reveal the chemi$\mathrm{cal}$ and dose responsible for these animal deaths (Bamberger and Oswald 2012).

The disposal of flowback water can be subject to several different EPA and statelevel regulations depending on whether it is discharged to surface water, injected in an underground well, or treated for reuse. Although once a valid concern, the practice of sending flowback to domestic wastewater treatment plants is becoming obsolete. Treating flowback at specialized treatment plants has increased the ability to reuse flowback fluid. The National Pollutant Discharge Elimination System regulates industrial waste disposal, such as flowback, to surface waters. Both the state and the EPA can issue a permit allowing discharge of pollutants into US surface waters. There are no guidelines for effluent limitations for such discharges of treated HVHF flowback fluids, as they are subject to the permit writer's assessment of the treatment technology available and the water-quality standards of the receiving waters (EPA 2011b). The direct discharge of untreated oilfield brines to surface waters is not permissible.

Flowback and produced waters from oil and gas operations are often disposed of in deep underground injection wells. These oilfield fluids are not considered by the EPA to be hazardous waste. Non-hazardous waste injection wells are regulated as Class II wells by the federal Safe Drinking Water Act, under the Underground Injection Control authority. The EPA can give regulatory authority to states if they further demonstrate the effectiveness of their program in preventing drinking water contamination (CRS 2013; EPA 2012).

Fact sheets provided by the oil and gas industry and state governments (see, e.g., http://www.michigan.gov/frackingfacts) may suggest that there is no likelihood of water contamination via disposal wells; however, it is not reasonable to entirely discount these wells as a risk for contamination. Rapid contamination of surface and groundwater by regulated disposal wells (not related to HVHF) has been documented in the Florida Keys (Paul et al. 1997). To be clear, this coastal scenario is very different hydrologically than the sites of typical inland disposal wells, such as those in Michigan. Still, this case does serve as an example of a regulated well that did not perform as intended.

\section{Post Production}

When wells are not producing enough natural gas to remain economical, they may be retired. It is important that decommissioned wells be properly plugged, as improperly plugged or abandoned wells can serve as a leakage conduit to the surface. 
A significant issue in some formations, such as the Marcellus, is that the location of older wells (some of which may have been abandoned or improperly plugged) is poorly documented. To reduce risk of litigation, to increase production of nearby wells, and to minimize possible threats to the local environment (e.g., CH4 leakage), improved efforts for proper well plugging are underway: for instance, by sealing with a series of cement plugs throughout the well and taking extra measures to seal the portion in contact with drinking waters (NPC 2012). Furthermore, the plugging of wells is regulated by the states to ensure that all operators follow best practices.

\section{Summary}

To best avoid potential risks related to HVHF, decision-making must be based on perceptions of risk that are not solely driven by emotions or misconceptions. We have provided context for HVHF risks in an effort to facilitate a clearer understanding of the HVHF process and associated risks. Many of the environmental concerns related to HVHF water resource impacts are similar in scope to those posed by other industrial practices. This is especially true when we compare HVHF with the broader energy-production and mining sectors. In addition, many of the issues related to public health concerns are not unique to HVHF activity. Full disclosure of chemical additives that may be released to the environment from all industries would be beneficial to environmental and public health researchers and practitioners. Extra care must be taken not to generalize possible risks and apply them broadly to all HVHF operations or, even more broadly, to all oil and gas drilling. Many of these risks will be site-specific, varying as a function of reservoir geology, water scarcity, and disposal opportunities. As an example, we could look at risk of fracture propagation into freshwater aquifers — this risk may be highest for HVHF occurring in especially shallow shale formations, and less of a concern for deeper HVHF completions.

The difficulty in defining the risks associated with HVHF activity serves as an excellent example of the overall complexity of the energy-water trade-offs that we face as a society. Throughout this paper, we touch on several important considerations for mitigating HVHF risks to water resources, including the importance of proper wastewater disposal and handling of waste fluids at the surface. Continued research and data collection will allow us to better understand the spectrum of risks 
posed by HVHF and enable the continued development of sound regulations that help ensure the safe and sustainable development of our domestic energy reserves.

\section{Acknowledgements}

We would like to thank the Michigan Journal of Sustainability for the invitation to contribute to its inaugural issue. We also want to thank the two anonymous reviewers for their thoughtful comments. BRE acknowledges funding support from the Michigan Society of Fellows and from the National Science Foundation under Grant No. 1214416.

\section{Disclosures}

The authors declare no competing financial interests.

\section{References}

Bäckstrand, Karin. 2003. "Civic Science for Sustainability: Reframing the Role of Experts, PolicyMakers and Citizens in Environmental Governance." Global Environmental Politics 3 (4): 24 41. http://dx.doi.org/10.1162/152638003322757916

Bamberger, Michelle, and Robert E. Oswald. 2012. "Impacts of Gas Drilling on Human and Animal Health." NEW SOLUTIONS: A Journal of Environmental and Occupational Health Policy 22 (1): 51-77. http://dx.doi.org/10.2190/NS.22.1.e

Barbot, Elise, Natasa S. Vidic, Kelvin B. Gregory, and Radisav D. Vidic. 2013. "Spatial and Temporal Correlation of Water Quality Parameters of Produced Waters from Devonian-Age Shale Following Hydraulic Fracturing." Environmental Science and Technology 47 (6): 2562-2569. http://dx.doi.org/10.1021/es304638h

Cathles, Lawrence M. III, Larry Brown, Milton Taam, and Andrew Hunter. 2012. "A Commentary on 'The Greenhouse-gas Footprint of Natural Gas in Shale Formations' by R. W. Howarth, R. Santoro, and Anthony Ingraffea." Climatic Change 113 (2): 525-535. http://dx.doi. org/10.1007/s10584-011-0333-0

Chiu, Yi-Wen, Brian Walseth, and Sangwon Suh. 2009. "Water Embodied in Bioethanol in the United States." Environmental Science and Technology 43 (8): 2688-2692. http://dx.doi. org/10.1021/es8031067

Congressional Research Service (CRS). 2012. "Hydraulic Fracturing: Chemical Disclosure Requirements." Accessed April 22, 2013. http://www.fas.org/sgp/crs/misc/R42461.pdf. 
. January 10, 2013. "Hydraulic Fracturing and Safe Drinking Water Act Regulatory Issues." Accessed April 22, 2013 www.fas.org/sgp/crs/misc/R41760.pdf.

Curtis, John B. 2002. "Fractured Shale-Gas Systems." AAPG Bulletin 86 (11): 1921-1938.

Davies, Richard J. 2011. "Methane Contamination of Drinking Water Caused by Hydraulic Fracturing Remains Unproven.” Proceedings of the National Academy of Sciences 108 (43): E871-E871. http://dx.doi.org/10.1073/pnas.1113299108

Davies, Richard J., Simon A. Mathias, Jennifer Moss, Steinar Hustoft, and Leo Newport. 2012. "Hydraulic Fractures: How Far Can They Go?" Marine and Petroleum Geology 37 (1): 1-6. http://dx.doi.org/10.1016/j.marpetgeo.2012.04.001

Dodson, Robin E., Marcia Nishioka, Laurel J. Standley, Laura J. Perovich, Julia Green Brody, and Ruthann A. Rudel. 2012. "Endocrine Disruptors and Asthma-Associated Chemicals in Consumer Products." Environmental Health Perspectives 120 (7): 935-943. http://dx.doi. org/10.1289/ehp. 1104052

DOE (US Department of Energy). 2006a. "Emerging Issues for Fossil Energy and Water." Accessed April 28, 2013. http://www.netl.doe.gov/technologies/oil-gas/publications/AP/IssuesforFEandWater.pdf.

2006b. "Energy Demands on Water Resources: Report to Congress on the Interdependency of Energy and Water." Accessed April 27, 2013. http://www.sandia.gov/energy-water/ docs/121-RptToCongress-EWwEIAcomments-FINAL.pdf.

2009. "State Oil and Natural Gas Regulations Designed to Protect Water Resources." Accessed April 22, 2013. http://www.gwpc.org/sites/default/files/state_oil_and_gas_regulations_ designed_to_protect_water_resources_0.pdf.

Dominguez-Faus, R., Susan E. Powers, Joel G. Burken, and Pedro J. Alvarez. 2009. "The Water Footprint of Biofuels: A Drink or Drive Issue?” Environmental Science and Technology 43 (9): 3005-3010. http://dx.doi.org/10.1021/es802162x

Druckman, James N., and Toby Bolsen. 2011. "Framing, Motivated Reasoning, and Opinions About Emergent Technologies.” Journal of Communication 61 (4): 659-688. http://dx.doi. org/10.1111/j.1460-2466.2011.01562.x

Engelder, Terry. 2012. "Capillary Tension and Imbibition Sequester Frack Fluid in Marcellus Gas Shale." Proceedings of the National Academy of Sciences 109 (52): E3625-E3625. http://dx.doi. org/10.1073/pnas.1216133110

EPA (US Environmental Protection Agency). 2004. "Evaluation of Impacts to Underground Sources of Drinking Water by Hydraulic Fracturing of Coalbed Methane Reservoirs; Chapter 4, Hydraulic Fracturing Fluids.” Accessed December 27, 2012. http://www.epa.gov/ogwdw/ uic/pdfs/cbmstudy_attach_uic_ch04_hyd_frac_fluids.pdf.

2011a. "Draft Investigation of Ground Contamination near Pavillion, Wyoming." Accessed December 27, 2012. http://www2.epa.gov/sites/production/files/documents/EPA_ReportOnPavillion_Dec-8-2011.pdf.

2011b. "Natural Gas Drilling in the Marcellus Shale NPDES Program Frequently Asked Questions." Accessed April 23, 2013. http://www.epa.gov/npdes/pubs/hydrofracturing_faq.pdf. 2012. "Class II Wells - Oil and Gas Related Injection Wells (Class II)." Accessed April 23, 2013. http://water.epa.gov/type/groundwater/uic/class2/index.cfm.

Fisher, Kevin, and Norm Warpinksi. 2012. "Hydraulic-Fracture-Height Growth: Real Data." SPE Production \& Operations 27 (1): 8-19. http://dx.doi.org/10.2118/145949-PA

FracFocus, Chemical Disclosure Registry. 2012. "Chemical Use in Hydraulic Fracturing." GWPC 
and IOGCC. Accessed December 27, 2012. http://fracfocus.org/water-protection/drillingusage and http://fracfocus.org/chemical-use/what-chemicals-are-used.

Galbraith, Kate. "As Fracking Increases, So Do Fears About Water Supply.” March 7, 2013. Accessed April 25, 2013. http://www.nytimes.com/2013/03/08/us/as-fracking-in-texas-increases-sodo-water-supply-fears.html?pagewanted=all\&_r $=0$.

Grady, C. P. Leslie Jr., Glen T. Daigger, .and Henry C. Lim. 1999. Biological Wastewater Treatment: Principles and Practice. New York: CRC Press

Gregory, Kelvin B., Radisav D. Vidic, and David A. Dzombak. 2011. "Water Management Challenges Associated with the Production of Shale Gas by Hydraulic Fracturing." Elements 7 (3): 181-186. http://dx.doi.org/10.2113/gselements.7.3.181

Haluszczak, Lara O., Arthur W. Rose, and Lee R. Kump. 2013. "Geochemical Evaluation of Flowback Brine from Marcellus Gas Wells in Pennsylvania, USA.” Applied Geochemistry 28 (January): 55-61. http://dx.doi.org/10.1016/j.apgeochem.2012.10.002

Hopkins, C. W., J. H. Frantz Jr., S.A. Holditch \& Assocs., Inc, D. Hill, Gas Research Institute, and F. Zamora, Halliburton Energy Services. 1995. "Estimating Fracture Geometry in the Naturally Fractured Antrim Shale.” Society of Petroleum Engineers Conference Paper. Dallas, Texas: Society of Petroleum Engineers. Paper No. 30483.

Howarth, Robert W., Anthony Ingraffea, and Terry Engelder. 2011. "Natural Gas: Should Fracking Stop?” Nature 477 (7364): 271-275. http://dx.doi.org/10.1038/477271a

Howarth, Robert W., Renee Santoro, and Anthony Ingraffea. 2011. "Methane and the Greenhousegas Footprint of Natural Gas from Shale Formations.” Climatic Change 106 (4): 679-690. http://dx.doi.org/10.1007/s10584-011-0061-5

Jenkins, Creties D., and Charles M. Boyer II. 2008. "Coalbed- and Shale-Gas Reservoirs.” Distinguished Author Series, Society of Petroleum Engineers (SPE). Accessed January 1, 2013. http://www.spe.org/jpt/print/archives/2008/02/JPT2008_02_17DAS.pdf.

Johnson, F. M. "How Many Food Additives Are Rodent Carcinogens?” 2002. Environmental and Molecular Mutagenesis 39 (1): 69-80. http://dx.doi.org/10.1002/em.10037

Kargbo, David M., Ron G. Wilhelm, and David J. Campbell. 2010. "Natural Gas Plays in the Marcellus Shale: Challenges and Potential Opportunities." Environmental Science and Technology 44 (15): 5679-5684. http://dx.doi.org/10.1021/es903811p

King, George E. 2012. "Hydraulic Fracturing 101: What Every Representative, Environmentalist, Regulator, Reporter, Investor, University Researcher, Neighbor and Engineer Should Know About Estimating Frac Risk and Improving Frac Performance in Unconventional Gas and Oil Wells." Society of Petroleum Engineers Conference Paper. Woodlands, Texas: Society of Petroleum Engineers. Paper No. 152596.

Michigan Energy Forum. 2012. "Michigan Energy Forum: Cheaper Natural Gas and Fracking and Their Economic and Environmental Impacts." Public event attended in Ann Arbor, MI at SPARK. December 6, 2012. Accessed December 27, 2012. http://www.slideshare.net/AnnArborMichigan Energy Forum/michigan-energy-forum-december-6-2012 and http://www. annarborusa.org/events/video-library/mef12-12.

Molofsky, Lisa J., John A. Connor, Albert S. Wylie, Tom Wagner, and Shahla K. Farhat. 2013. "Evaluation of Methane Sources in Groundwater in Northeastern Pennsylvania." Groundwater 51 (3): 333-349.

Montgomery, Carl T., and Michael B. Smith. 2010. "Hydraulic Fracturing-History of an Enduring Technology Special Section.” Journal of Petroleum Technology 62 (12): 26. 
Myers, Tom. 2012. "Potential Contaminant Pathways from Hydraulically Fractured Shale to Aquifers." Ground Water 50 (6): 872-882. http://dx.doi.org/10.1111/j.1745-6584.2012.00933.x

National Petroleum Council (NPC). "Paper \#2-25 Plugging and Abandonment of Oil and Gas Wells.” September 15, 2011. Accessed January 2, 2013. http://www.npc.org/Prudent_ Development-Topic_Papers/2-25_Well_Plugging_and_Abandonment_Paper.pdf

Nicot, Jean-Philippe, and Bridget R. Scanlon. 2012. "Water Use for Shale-Gas Production in Texas, U.S.” Environmental Science and Technology 46 (6): 3580-3586. http://dx.doi.org/10.1021/ es204602t

NYSDEC (New York State Department of Environmental Conservation). 2011. "Well Permit Issuance for Horizontal Drilling and High-Volume Hydraulic Fracturing to Develop the Marcellus Shale and Other Low-Permeability Gas Reservoirs.” Accessed April 24, 2013. http:// www.dec.ny.gov/docs/materials_minerals_pdf/rdsgeisexecsum0911.pdf.

Osborn, Stephen G., Avner Vengosh, Nathaniel R. Warner, and Robert B. Jackson. 2011a. "Methane Contamination of Drinking Water Accompanying Gas-well Drilling and Hydraulic Fracturing." Proceedings of the National Academy of Sciences 108 (20): 8172-8176. http://dx.doi. org/10.1073/pnas.1100682108

. 2011b. "Reply to Saba and Orzechowski and Schon: Methane Contamination of Drinking Water Accompanying Gas-well Drilling and Hydraulic Fracturing." Proceedings of the National Academy of Sciences 108 (37): E665-E666. http://dx.doi.org/10.1073/pnas.1109270108

Pacific Institute. June 2012. "Separating the Frack from the Fiction.” Accessed December 27, 2012. http://www.pacinst.org/reports/fracking/full_report.pdf.

Paul, John H., Joan B. Rose, Sunny C. Jiang, Xingting Zhou, Pamela Cochran, Christina Kellogg, Jordan B. Kang, Dale Griffin, Samual Farrah, and Jerzy Lukasik. 1997. "Evidence for Groundwater and Surface Marine Water Contamination by Waste Disposal Wells in the Florida Keys." Water Research 31 (6): 1448-1454. http://dx.doi.org/10.1016/S0043-1354(96)00374-0

Rozell, Daniel J., and Sheldon J. Reaven. 2012. "Water Pollution Risk Associated with Natural Gas Extraction from the Marcellus Shale." Risk Analysis 32 (8): 1382-1393. http://dx.doi. org/10.1111/j.1539-6924.2011.01757.x

Saba, Tarek, and Mark Orzechowski. 2011. "Lack of Data to Support a Relationship Between Methane Contamination of Drinking Water Wells and Hydraulic Fracturing." Proceedings of the National Academy of Sciences 108 (37): E663-E663. http://dx.doi.org/10.1073/ pnas. 1108435108

Schon, Samuel C. "Hydraulic Fracturing Not Responsible for Methane Migration." 2011. Proceedings of the National Academy of Sciences 108 (37): E664-E664.

Slovic, Paul, Melissa L. Finucane, Ellen Peters, and Donald G. MacGregor. 2004. "Risk as Analysis and Risk as Feelings: Some Thoughts About Affect, Reason, Risk, and Rationality." Risk Analysis 24 (2): 311-322. http://dx.doi.org/10.1111/j.0272-4332.2004.00433.x

Stamm, Keith R., Fiona Clark, and Paula Reynolds Eblacas. 2000. "Mass Communication and Public Understanding of Environmental Problems: The Case of Global Warming." Public Understanding of Science 9 (3): 219-237. http://dx.doi.org/10.1088/0963-6625/9/3/302

Steinemann, A. C., I. C. MacGregor, S. M. Gordon, L. G. Gallagher, A. L. Davis, D. S. Ribeiro, and L. A. Wallace. 2011. "Fragranced Consumer Products: Chemicals Emitted, Ingredients Unlisted." Environmental Impact Assessment Review 31 (3): 328-333. http://dx.doi. org/10.1016/j.eiar.2010.08.002 
USGS (US Geological Survey). 2009. “Estimated Use of Water in the United States in 2005.” Accessed April 25, 2013. http://pubs.usgs.gov/circ/1344/pdf/c1344.pdf.

Wagner, Bernard M. 2003. "Food Additives and Cancer: Banging the Drum." Toxicologic Pathology 31 (3): 348-349.

Wang, Xiuli, and Michael Economides. 2009. Advanced Natural Gas Engineering. Houston: Gulf Publishing Company. 400 pp.

Warner, Nathaniel R., Robert B. Jackson, Thomas H. Darrah, Stephen G. Osborn, Adrian Down, Kaiguang Zhao, Alissa White, and Avner Vengosh. 2012. "Geochemical Evidence for Possible Natural Migration of Marcellus Formation Brine to Shallow Aquifers in Pennsylvania." Proceedings of the National Academy of Sciences 109 (30): 11961-11966. http://dx.doi. org/10.1073/pnas.1121181109

Weber, Christopher L., and Christopher Clavin. 2012. "Life Cycle Carbon Footprint of Shale Gas: Review of Evidence and Implications.” Environmental Science and Technology 46 (11): 5688 5695. http://dx.doi.org/10.1021/es300375n

Zartarian, V. G., W. R. Ott, and N. Daun. 1997. "A Quantitative Definition of Exposure and Related Concepts." Journal of Exposure Analysis and Environmental Epidemiology 7 (4): 411-438. 